\title{
The use of chickens to remove the infective stage of Haemonchus contortus from the field after sheep have grazed
}

\author{
Jessica Harley Nicole Eddy \\ West Virginia University
}

Follow this and additional works at: https://researchrepository.wvu.edu/etd

\section{Recommended Citation}

Eddy, Jessica Harley Nicole, "The use of chickens to remove the infective stage of Haemonchus contortus from the field after sheep have grazed" (2008). Graduate Theses, Dissertations, and Problem Reports.

2736.

https://researchrepository.wvu.edu/etd/2736

This Thesis is protected by copyright and/or related rights. It has been brought to you by the The Research Repository @ WVU with permission from the rights-holder(s). You are free to use this Thesis in any way that is permitted by the copyright and related rights legislation that applies to your use. For other uses you must obtain permission from the rights-holder(s) directly, unless additional rights are indicated by a Creative Commons license in the record and/ or on the work itself. This Thesis has been accepted for inclusion in WVU Graduate Theses, Dissertations, and Problem Reports collection by an authorized administrator of The Research Repository @ WVU. For more information, please contact researchrepository@mail.wvu.edu. 
The use of chickens to remove the infective stage of Haemonchus contortus from the field after sheep have grazed

\author{
Jessica Harley Nicole Eddy
}

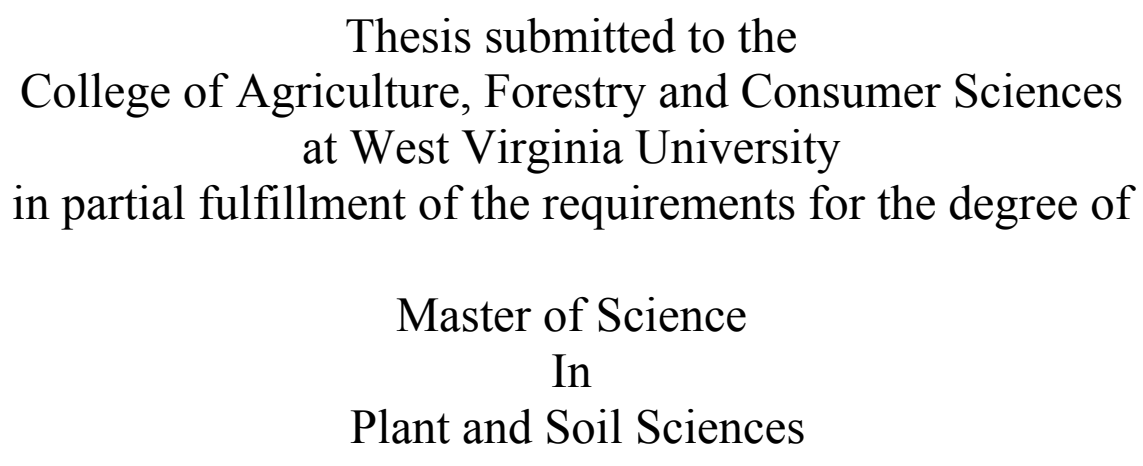
Dr. William Bryan Ph.D., Chair
Dr. Margaret Minch D.V.M.
Dr. James Kotcon, Ph.D.

Division of Plant and Soil Sciences

Morgantown, West Virginia

2008

Keywords: Haemonchus contortus, sheep, Ovis aries, chicken, Gallus domesticus, rotational grazing

Copyright 2008 Jessica Harley Nicole Eddy 


\begin{abstract}
The use of chickens to remove the infective stage of Haemonchus

contortus from the field after sheep have grazed
\end{abstract}

Jessica Harley Nicole Eddy

There are few USDA organic certified practices for controlling the nematode Haemonchus contortus. This small ruminant parasite has a life cycle that makes it a candidate for control using field rotations. The third-stage of the nematode's life cycle is responsible for infecting or re-infecting a host and the use of chickens to control $H$. contortus has not been tested. This experiment was conducted to determine if the chicken's foraging behavior reduces the number of infective third-stage larvae on the pasture by comparing a chicken sub-plot, a subplot that was mowed, a control sub-plot and a pretreatment. These forage removal methods were applied to areas of a pasture infested with L3 larvae and two weeks after the end of treatment L3 counts per gram of forage were calculated. There was no significant difference between the forage removal methods, but there was a numerical trend showing that the chickens reduced the number of nematodes in comparison to the control. Different chicken management might increase the effects of the treatment. 


\section{Dedication}

This work is dedicated to an individual whose faith in knowledge could not be curbed by any person, beast or force of nature. His wisdom and loving guidance is happily remembered. May we one day speak again.

Edwin Harley 1942-2003 


\section{Acknowledgements}

Many thanks go to those who have assisted in this exploration into the uncertain. Thanks especially to Dr. Kotcon and the Nematology Lab staff for allowing the use of their facilities, the WVU Organic Research Farm staff for their assistance in the field, and Dr. Moritz for the use of the chickens. Thank you, Dr. Minch for supplying several helpful resources and insight. Also, thank you Dr. Bryan for the research advice and guidance. I would also like to thank my family and friends for their support, and chicken 346 for her patience and cooperation. 


\section{Table of Contents}

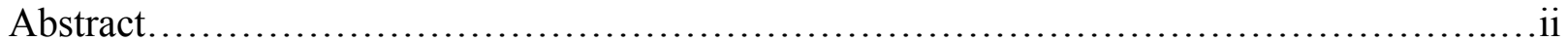

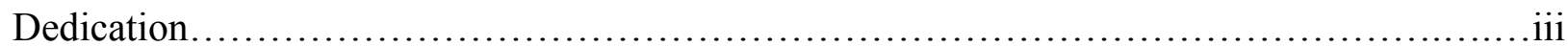

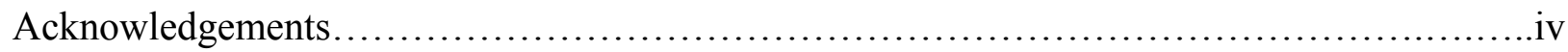

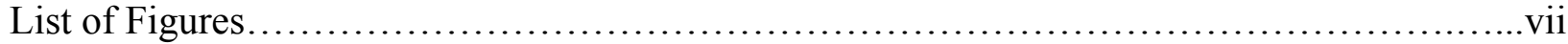

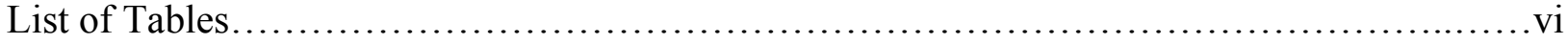

Literature Review

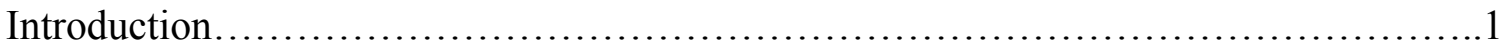

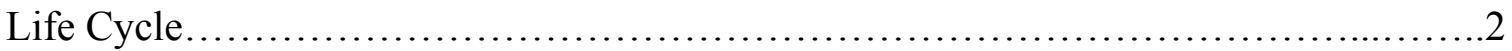

Survival and Feeding in the Host.....................................................

Effect of the Weather............................................................ 6

Movement on Forage and Soil.................................................. 9

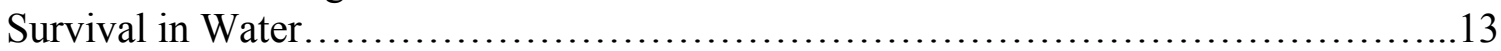

Identification of $H$. contortus................................................ 14

Identification of an Infected Animal............................................ 15

Extraction from Forage......................................................... 18

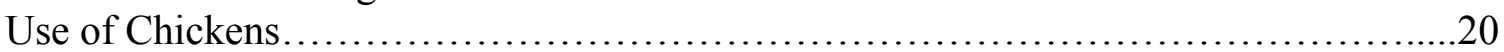

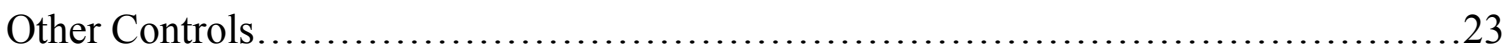

Materials and

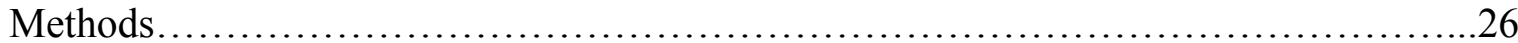

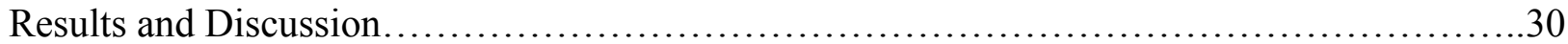

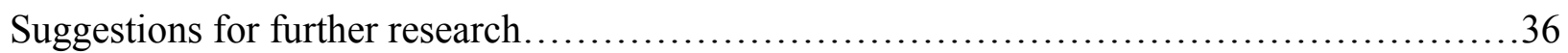

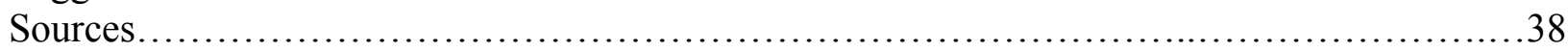

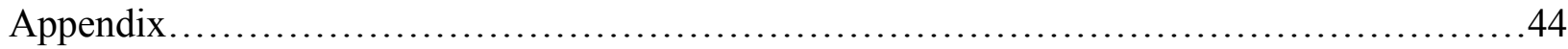

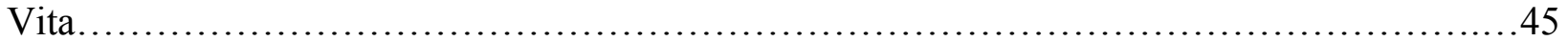




\section{List of Tables}

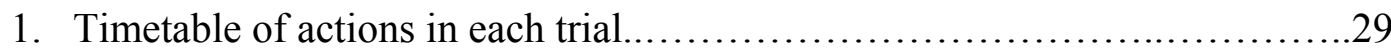

2. Model significance levels of the number of nematodes found per gram of forage dry matter (DM) and per sub-plot, and forage mass DM, pretreatments included.

3. Effect of treatment and pretreatment on nematodes and forage DM...........31

4. Maximum and minimum temperatures and precipitation for the days on which forage was clipped................................................... 32

5. Model significance levels of the number of nematodes found per gram of forage dry matter (DM) and per sub-plot, and forage mass DM, treatments

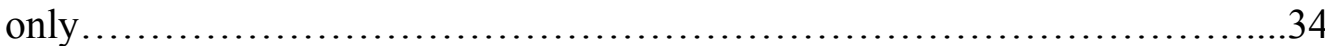

6. Effect of trial on nematodes and forage DM........................... 34

7. Average monthly temperature for the months of the experiment, deviation from the thirty year average and monthly precipitation...........................36

Appendix

1. Number of chickens in each sub-plot each day of chicken grazing. .44 


\section{List of Figures}

$\begin{array}{lll}\text { Figure } & \text { Page }\end{array}$

1. Effect of forage removal treatment and trial on the DM of forage.............36 


\section{Introduction}

One of the biggest problems in organic sheep production, in West Virginia, is when gastrointestinal parasites feed on the sheep by sucking blood. A sheep that is overburdened with intestinal worms usually must be treated to kill the worms with a chemical prohibited for use under organic rules hence the sheep can no longer be certified organic. One of the major worms in question is Haemonchus contortus a.k.a. the barber pole worm. It feeds on the animals from the stomach lining and passes its eggs to the field in the feces. There the egg develops into the infective stage of the worm, that when ingested by a sheep during grazing, infects that animal and the cycle continues.

Animals that are non-ruminants; horses, pigs, donkeys, mules and avian species such as

chickens, are not infected by $H$. contortus. This study evaluated whether grazing a field infected with $H$. contortus L3 with a non host animal, such as chickens will reduce the number of the infective larva in the field. 


\section{LITERATURE REVIEW}

\section{Life Cycle}

The adult stage of $H$. contortus is located in the abomasum of sheep where it is a blood sucker. The adult passes the eggs to the stomach contents which then exit the body as a part of the animal's feces. The feces land on the ground where the eggs hatch and progress through two molts. The resultant third stage larva climbs up the forage by swimming in the moisture on the plant to be ingested by another herbivore (Smith et al., 2006).

Once eaten by a suitable ruminant host the third-stage larva exsheaths. After exsheathment, the worm passes into the abomasum where the unsheathed third stage larva burrows into the mucosa (Olsen, 1974). After feeding for a time the nematode molts again to become the fourth stage larva. In the lumen of the abomasum the nematode continues to feed and undergoes a fifth molt before sexual maturity is complete (Smith, 1942; Sendow, 2003). The worm is sexually mature 14 to 21 days after being ingested as an L3 (Olsen, 1974). In the adult stage the worm can consume $0.05 \mathrm{ml}$ of blood per day (Elmer et al., 1989). After L3 inoculation nematode eggs can be seen in sheep feces in 21 days (Levine et al, 1977).

Copulation in the nematode involves the coiling of the male around the female adult. The male will use spicules to hold the female in place while sperm are deposited in the genital pore of the female (Sendow, 2003). The adult female can lay 5,000 or more eggs per day on average (Olsen, 1974). The critical infection level is believed to be 500 adult worms in a single sheep (Krull, 1969). The time it takes for the egg to hatch and develop is dependant upon factors that include temperature, humidity and precipitation. Infective larva cannot move far, so all that is needed to keep the sheep from being infected is for them to be removed from these infectivestage three larva. 
After the eggs land on pasture and hatch, an act that will require between two days and two weeks, the first stage larva will emerge. This larva will feed on microorganisms in the fecal pellet of the sheep. After a time, these will molt into the second stage larva that also has the mechanisms and the need to feed on microorganisms in the fecal pellet (Levine et. al., 1974). Finally, this second stage will molt into the third stage larva which can climb up the forage by swimming in dew drops or it may stay in fecal remains, meaning that it may not climb the forage at all. In this case, the infective larva will be in a less prime spot for ingestion and may be more likely to die without achieving host parasitism.

The infective stage larva has an outer cuticle called a sheath that must be removed for the third stage larva to develop into the fourth stage. After ingestion, these third stage nematodes may be known as sheathed fourth stage larva. Then, the sheath and cuticle of the infective stage larva slough off. The events that must occur to promote exsheathment of the infective larva are related to an external stimulus and receptors on the nematode (Murphy and Summerville, 1983). These receptors can be activated in the presence of forty percent carbon dioxide and a temperature of $39^{\circ} \mathrm{C}$, conditions found in the rumen.

Symptoms of $H$. contortus infection can be duplicated by bleeding the animal (Krull, 1969). Russian research has shown that the worms produce other side effects. It is claimed that there is a change in carbohydrate metabolism and that "aplastic anemia results from a disturbance of the neuro-humoral regulation of the haemopoietic system" (Krull, 1969 p51). Evidence has also been found for a shift towards a neutral $\mathrm{pH}$ in the abomasum. This shift can affect other processes in the body. The $\mathrm{pH}$ change can be reversed by the addition of $\mathrm{HCl}$ to the drinking water with glucose insulin therapy for assistance in carbohydrate metabolism (Krull, 1969). 
The first-stage (L1) of the nematode has been described in detail by Veglia (1915). The mouth of the L1 is distinguished by having six small dots around the circumference of the circular opening. The mouth ends in a buccal cavity that can be seen as having walls that appear as two lines ending in two dots. The worm has a lumen that appears in a zigzag pattern. The worm is active upon first hatching, but after a time this behavior stops and the worm becomes sedentary. This lack of movement changes after the nematode has filled its gut cavity with food granules from bacteria in the feces. After the nematode has finished feeding, it takes on a rigid stance and becomes shaped like a comma. The nematode then sheds its skin in the first ecdysis.

The second-stage nematode removes its first-stage cuticle by scraping it off in the feces. As the nematode ages the zigzag intestine straightens out and increases in size. Once the L2 have fed, they have been observed moving to the center of the medium or sinking to the bottom after suspension in water. In the change to the L3 stage, the L2's mouth will change shape along with the buccal cavity and esophagus. The L3 nematode exsheaths within the host by escaping the confines of the sheath as if it were a shell. The cuticle or sheath, forms a ring around the anterior end of the worm. The worm withdraws its head and will twist its body within the sheath. The twisting of the body can be seen as the anus of the worm and the anus opening in the sheath will no longer line up after twisting. The sheath will also swell during ecdysis. The cuticle will start to separate at the site of the ring. The worm will emerge from the opening and will rip the cuticle laterally as it exits (Gamble et al. 1989). 


\section{Survival and Feeding in the Host}

Anemia is a result of blood feeding by the parasitic worm and from excess bleeding that results from the worm's anticoagulant agents. The worm will feed for a period lasting about twelve minutes. Once the worm ceases to feed, the bleeding does not stop and the wound will continue to bleed for an approximate average of seven minutes. The blood loss per worm can range from $0.003 \mathrm{ml}$ to $0.05 \mathrm{ml}$ (Le Jambre, 1994). A sheep can lose more than $400 \mathrm{ml}$ of blood a day due to a $H$. contortus infection (Le Jambre, 1994). Adult females producing eggs at a normal rate and populations of adult females without functioning ovaries do not significantly differ in the amount of blood consumed. The metabolitic requirement is expected to change in producing females, but because the feeding habits do not change, it is assumed that excess nutrients are consumed in times of stagnant egg production (Le Jambre, 1994).

Coyne et al. (1991) found that the length of time $H$. contortus can live in six month old lambs averaged 100 days. This average was derived from experiments where lambs were infected with a single dose of the nematode. The dose ranged in number from 500 to $20,000 \mathrm{~L} 3$ larvae.

An experiment done by Ayalew and Murphy (1986) involved the removal of nematodes from the stomach of freshly slaughtered sheep and the placement of these nematodes in a vessel that simulated conditions in the abomasum of the sheep. The adults were observed and after the fourth or fifth day the nematodes were no longer strongly active and by the eighth day there was very little movement at all. However, the nematodes maintained their color and shape. After the $12^{\text {th }}$ day eggs in inactive gravid females were hatching into the L1 stage. This occurred in 80 to $85 \%$ of the gravid worms. Twenty-four hours later, the L2 stage could be seen still inside the female. The L3 developed 2 to 3 days later and they also exsheathed in the female. The late L4 
stage could be observed by the $18^{\text {th }}$ day of incubation. The nematodes, whether they were at the L3 or L4 stage in the adult female, exited by a body opening such as the rectum or via disintegration of the cuticular sac of the dead female (Ayalew and Murphy, 1986). This suggests that a sheep does not have to consume infected pasture to maintain a parasite infection if it has already been exposed at some point. The host can become re-infected without ingesting more infective larva.

Irrespective of oviparous source or viviparous origin, the worms obtain blood from the animal with the use of a lancelet, a needle-like appendage, resulting in hemoraging. The amount of hemorrhaging depends on the level of infestation. In heavily infected animals red pigment can be seen in the stomach contents from the bleeding that occurs even after the nematode is finished feeding.

\section{Effect of the Weather}

Two experiments done by Levine and others (1974) in Urbana, IL involved the placement of H. contortus-infected feces on fourteen $55-\mathrm{cm}^{2}$ pasture plots with laboratory controls. Their experiments spanned six years and totaled almost 150 replications or series for each experiment. Their records also included meteorological and micrometeorological data. Of the two experiments, one dealt with feces containing eggs and one with feces containing infective larvae. The feces were obtained from nine isolated young sheep inoculated with $H$. contortus. The breed of sheep used was not reported. The feces were then immediately taken to the lab and kept at room temperature and humidity.

On the first day of the egg experiment, fourteen plots were seeded with 50 to $100 \mathrm{~g}$ of feces with a mean of approximately 5,000 eggs per gram. Every day for seven days, a researcher 
collected some of the feces from different plots. In the lab, the fecal pellets were split in half. In one half, the number of eggs was determined and the other half was incubated for one week at $100 \%$ relative humidity and $36^{\circ} \mathrm{C}$. By comparing the numbers of eggs to infective larvae in the lab they were able to determine the viability of unhatched eggs in the feces from the field. They also collected data on persistence of feces. Pellets lasted longer when the precipitation and the temperature were low.

The second part of their paper dealt with infective larvae in feces incubated for one week. Fifty to one-hundred grams of feces with infective larvae were placed on each of the 14 plots on the first day of each series. They then used soil surface scrapings, grass clippings, and fecal pellet recovery once a week to estimate the number of infective nematodes present. They determined that infective larvae reared in the lab and placed in the field lived longer than those larvae that hatched there from egg placement. Infective larvae hatched from eggs in the field were recovered for up to 38 days whereas those reared in the lab and placed in the field were recovered for up to 58 days. Researchers could not find a relationship between the longevity of the infective third-stage larva and temperature except that larvae were not present in the winter months. Also, when the temperature was below $10^{\circ} \mathrm{C}$ almost no larvae were recovered. When the temperature was above $20^{\circ} \mathrm{C}$, recovery was below $1 \%$ of those placed on the field. However, $43 \%$ of the time when egg-inoculated fecal pellets were placed on the field no eggs were recovered the next day. Researchers admitted that improvements could be made in their methods of recovering the nematodes from vegetation, soil and fecal material.

Larvael survival is dependent upon egg survival as well. The length of time an $H$. contortus egg can survive on pasture is more highly dependent on environmental conditions than that of the L3. Dinaburg (1944) found that when eggs of H. contortus were exposed to mean 
maximum temperatures below $65^{\circ} \mathrm{F}$ no infective larvae could be found in the field when sampled at or after thirteen days. The data were consistent regardless of the amount of rainfall. Few pre infective larvae, L1 or L2, were found in the field at 3 to 6 days, showing that at least some of the eggs hatched. Rainfall came to be an important factor after the temperature requirement for the development of the worm had been satisfied. The optimum temperature at which the nematodes can develop is 66 to $84^{\circ} \mathrm{F}$ and at these temperatures rainfall can improve the rate of development.

The ability of the worm to survive various temperatures was studied at each life stage. The egg cannot develop at temperatures above $95^{\circ} \mathrm{F}$ nor can it develop after drying. The $\mathrm{L} 1$ and L2 stages are also susceptible to death by drying. The infective larvae can live at $122^{\circ} \mathrm{F}$ for approximately two hours and it can also survive $108^{\circ} \mathrm{F}$ for one month. Oven drying is lethal to the L3 stage but it can survive for a few days in the absence of water. However, if the L3 is only air dried, at room temperature with natural evaporation, indoors, the nematode can live for approximately 4.5 months (Mönnig, 1930). The L3 stage can withstand being held at $32^{\circ} \mathrm{F}$ for 6 to 7 months (Veglia 1915). This is supported by the information that the adult stage (L5) of the nematode becomes hypobiotic in the animal when environmental conditions are such that the free living stages (egg L1, L2, L3) cannot survive (Elmer et al., 1989). Veglia (1915) also determined how long it takes for eggs to hatch. At $26^{\circ} \mathrm{C}$ in the dark $25 \%$ hatched after 14 hours, $50 \%$ after 17 hours and, if all eggs were viable, the rest hatched by the 48 -hour mark. 


\section{Movement on Forage and Soil}

Field studies were conducted by Rees (1948) to determine where on the forage and in the soil the nematode $H$. contortus could be found at different times of the day. Twelve grass plots were used for the 24-hour period. The plots were specially treated for the experiment to have the same conditions. Three-week growth of Lolium perenne, cut to $3 \mathrm{~cm}$, was used. At midnight 1200 L3 H. contortus larvae were poured evenly at the base of the grass in each plot with a pipette and every two hours soil and herbage on a plot was sampled. Counts were made for the recovery of L3 from the following layers: top $5 \mathrm{~cm}$ soil, top $2 \mathrm{~cm}$ grass, bottom $1 \mathrm{~cm}$ grass. The process was repeated once a month for one year and micrometeorological data were recorded. Nematodes were recovered by placing the entire sample in a Baermann apparatus.

It was concluded, based on the findings of the experiment, that the vertical migration of infective larvae is a response to light intensity. The maximum recoveries of nematodes on forage were when the light intensity fell between 15 to 560 foot candles. In general, most nematodes were recovered early in the morning or late in the day. A trend was also seen in the morning hours, that the time of highest recovery became earlier as the seasons changed from winter to summer. It was also noted that migration was reduced but not stopped by rainfall.

Based on the findings of Veglia (1915) it is understandable that the L3 nematodes do not stay on forage at all times because if they did, without any additional moisture, only $10 \%$ would be alive after 24 hours. Height of climb is variable and determined by the health and energy stores of the individual worm. At $20^{\circ} \mathrm{C}$ overnight the nematode is capable of climbing 10 to 14 cm vertically (Veglia, 1915).

Survival rates can be influenced by how the eggs of $H$. contortus are deposited in the sheep feces. Depending on the condition of the infected animal, feces can be put onto pasture in 
conditions ranging from whole pellets to runny diarrhea (a.k.a. runny paste). In a plot comparison experiment, Shorb (1942) determined that feces reduced to a paste favored the survival of the nematode, when compared to pelleted feces, as it prevented the dehydration of the eggs. Therefore, diarrhea may enhance the survival chances of the worm. It was also noted that more nematodes were recovered when the feces was applied in piles that conserved moisture. This experiment also had treatments with varying amounts of water sprinkled on the plot. The trend documented indicates that the more water poured on the plot, up to one quart, the more nematodes were recovered. The treatment that benefited the survival of $H$. contortus the most was a plot with 1 quart of water sprinkled daily where the eggs were applied in a watery paste of feces heaped in the center of the plot.

Shorb (1942) also conducted an experiment to determine how helpful grass is to the survival of $H$. contortus under field conditions. Two sub-plots were used. One had all the grass and one inch of soil removed. The other was left with forage intact to serve as a control plot. Both plots were infected with sheep feces and the treatment plot's nematode population was counted when the forage and soil were removed. There were 988 larvae in the soil and 376 in the grass, and these came from a feces inoculation containing 6,900,000 eggs. Once the soil and forage were removed in the treatment plot $27,2652^{\text {nd }}$ and $3^{\text {rd }}$ stage larvae were added. One week later the plots were sampled and only 21 larvae could be recovered from the treatment plot while the control plot harbored 6,070 larvae. The author notes that these results came about despite there being sunshine only about half the time and the total rainfall being significantly above average.

Experiments show that the L3 nematode survival chances increase if the worm is on the shaded side of a blade of grass. Veglia (1915) found 20 to $30 \%$ of the nematodes used in the 
experiment, on the shaded side of grass blades while the sunny side had no living L3 nematodes. In a similar experiment that was done directly on soil, it was determined that $97 \%$ of the infective larvae died when placed in direct sunlight.

Soil type can affect the longevity of the larvae in the field. The main effects of the soil deal with the influence soil type has on five survival factors as described by Mönnig (1930 p192):

1. Larval exhaustion: Loss of fat stores for energy

2. Desiccation: General damage

3. Temperature: Heat promotes drying out, cold intolerance

4. Exsheathment: Loss of protection afforded by the sheath due to friction

5. Sunlight factor: Promotes drying out

Monnig (1930) noticed that downward migration below the soil surface is more prominent in sandy loam than in clay soils. Migration in soil is also affected by rain. In an experiment done by Mönnig (1930), pots watered from the bottom had infective larvae that lived longer than those in pots watered from the top. Due to the water flow in the pots watered from the top the nematodes seem to have expended energy to stay near the surface of the soil. The nematode will also live longer in sandy than in clay soil because of the pore space in the soils. The large connected pore space in sandy soils allows the nematodes to move more easily, thus expending less energy, than in clay soils that have tighter pore spaces. Also, the sandy soils allow the nematode to migrate deeper into the soil. This becomes advantageous in the winter where freezing temperatures can be avoided by migrating deep into the soil. Rubbing against soil particles could potentially encourage early exsheathment but Veglia (1915) noted that exsheathed nematodes can survive if left in water (1915). 
Krecek et al. (1995) compared recovery rates of L3 H. contortus nematodes, developed from feces put on pasture, at 17 and $27{ }^{\circ} \mathrm{C}, 32$ and $72 \%$ relative humidity, 17 and $37 \%$ soil moisture, 0.5 and $1.3 \mathrm{~m} / \mathrm{s}$ wind speed, and 26 and $66 \%$ of sunlight. Four strata of the pasture were examined for the presence of the nematode. The strata were upper forage, lower forage, mat and soil. They could find no significant effect of wind speed and percent illumination on L3 location in the forage or soil. However, air temperature and soil moisture had the greatest effect on location of the nematodes. When soil moisture was at $37 \%$ more nematodes were found in the upper portion of the herbage compared to soil moisture at $17 \%$. When the air temperature was $27{ }^{\circ} \mathrm{C}$ more nematodes were found in the upper portion of the herbage than at $17^{\circ} \mathrm{C}$. High relative humidity significantly increased the nematode count in the forage but this seemed to have a smaller effect than air temperature and soil moisture that had a more significant effect.

Khalil (1922) showed that $H$. contortus was neither attracted by nor repelled by heat. However, under natural conditions, the L3 nematode will migrate to areas shielded from direct sunlight (Veglia, 1915). The first-stage, L1, does not migrate far enough to save itself if it gets caught in unfavorable conditions. Furthermore, a single nematode will dry out and die more quickly than a cluster of L3 nematodes (Veglia, 1915). The clustering behavior may act as a means of survival for nematodes in a small basin of water that is slowly drying up. In very wet soils $H$. contortus larvae have been observed as deep as $15 \mathrm{~cm}$. This was seen as a means to escape unfavorable conditions. In more favorable conditions the nematode has been seen as deep as $5 \mathrm{~cm}$ (Veglia, 1915). H. contortus has a tendency to migrate out of the medium from which it developed from the egg stage.

The L3 is not able to climb on vertical clean glass surfaces but, if given a medium, it will migrate up the side of the container just as if it were grass. On the same note, they will also 
climb a stick placed on top of feces. Observations made by Veglia (1915) showed that the L3 are also capable of stretching upwards or reaching up in an attempt to get to a higher point. Evidence shows that nematodes are programmed to leave the fecal pellet once they have matured to the L3 stage.

\section{Survival in Water}

As the worm in all of its stages can be exposed to different pasture habitats its survival in water that can be drunk by sheep becomes another mode of infection. According to Veglia (1915) only a small proportion of eggs can hatch in stagnant water of a depth greater than 0.5 $\mathrm{cm}$. The larvae will die in similar aquatic conditions in 12 to 15 days, perhaps due to a lack of oxygen in the water.

Mönnig (1930) conducted an experiment where a pure sample of $H$. contortus eggs was placed in $3 \mathrm{~cm}$ of water with fine particles from feces that accompanied the eggs through a sieve. The eggs were sampled regularly for hatchability. The longest trial after which $H$. contortus eggs were still viable after being submerged in $3 \mathrm{~cm}$ of water was 45 days. The author noted that no eggs hatched or developed underwater.

When populations of the nematode are in motion on forage they form a branching pattern. To avoid drying out the nematodes stay together but they do not move in clumps. They move in a chain where each L3 nematode is in contact with another forming a complex system of branches that spread over the occupied surface. The benefit of this behavior is that when a drop of water falls on the semi dry branching system, the water has a better chance of reaching more of the larval nematodes and preventing them from drying out completely (Veglia, 1915). It is a 
behavior that encourages a capillary reaction that aids the survival of the nematode. The branching movement also concentrates the nematodes in the herbage.

\section{Identification of $\boldsymbol{H}$. Contortus}

H. contortus eggs can be distinguished from other species of nematodes by their thin shelled eggs. Egg comparisons were made by Tetley (1941) using an ocular micrometer to measure eggs and pregnant females of identified species. Eggs were recovered from fecal material using the Stoll method, salt flotation and centrifuging. It was determined that $H$. contortus eggs range in size from 76 to $85 \mu$ by 41 to $48 \mu$. Size may depend on the strain of $H$. contortus, host and method of egg recovery. Eggs under a microscope appear as ovals with small dark circular lumps that entirely fill the oval with the highest concentration being in the center of the oval.

The third stage larva in the strain infecting ox tapers off with the narrowest end being the tail. It can be distinguished from other strains by a kink in the tail that is immediately posterior to the tip of the tail. The length of the third stage larvae varies between $749 \mu$ and $866 \mu$. There is also an extension of the sheath beyond the tip of the tail that can be anywhere from 158 to $193 \mu$. The sheep strain of $H$. contortus differs by being shorter in the tail (Krull, 1969). Further details distinguish it from other species. The head is round, not square and the tail is described as being medium in length especially when compared to the long tailed third stage Nematodirus nematode that is also a sheep parasite(RVC, 2008). The sheath is easiest to see when the nematode bends in movement where the bumps of this protective covering are seen on the innermost side of the coiled worm. 
The adult stage of the nematode found in the abomasum of its host can range from 10 to $20 \mathrm{~mm}$ in length if it is a male and 18 to $30 \mathrm{~mm}$ if the worm is a female. The female has a linear ovary that wraps around a red intestine to give it the appearance of a barber's pole. The worm also has a lancelet in the buccal cavity. Flap-like cervical papillae can be found in this worm along with cuticular markings. The male has a well developed bursa complex with a large pair of lateral lobes that are supported by slender rays and an asymmetrical dorsal lobe attached to the left lobe that is supported by a y-shaped dorsal ray. This dorsal lobe is a distinguishing characteristic of this worm that separates it from other species that may also be found in the abomasum. The worms also have a spiracle shape similar to that of a crochet hook. One can also find on this worm a gubernaculum that is long, flat and fusiform (Krull, 1969).

\section{Identification of an Infected Animal}

Sheep that are infected with this parasite will appear emaciated and run down. The head will start to hang and the ears often droop. The animal will have a more obvious tendency to walk down hill even if its herd mates are headed up the hill. The animal will become anemic due to blood lost to the internal parasites. There can also be seen in infected sheep the swelling of the lower jaw which is a condition called bottle jaw. The swelling seen in bottle jaw is due to the accumulation of fluids in the lower mandible. Inconsistently, there may be either diarrhea or constipation (Krull, 1969). The eyes can appear to be sunken and there may be a loss of appetite (Krull, 1969).

Newborn lambs are exempt from infection with $H$. contortus. The rumen of the lamb is not yet fully developed and does not allow the nematode to exsheath (Hertzberg et al., 2002). 
Nematode infestation changes the conditions of the stomach within the animal. In the case of $H$. contortus gut motility can be altered along with reduced gastric secretion. Changes in $\mathrm{pH}$ are seen as an increase from normal. It has also been observed that the mucosa of the stomach is easier for nematodes to penetrate when there is already an infection. Hormonal changes can also occur, such as an increase in gastrin and enteroglucagon (Beckage, 1997). These internal changes could be responsible for some of the observable symptoms.

Anemia can be diagnosed based on the appearance of the skin. A professional scale used to rank the level of anemia in sheep and goats is the FAMACHA ${ }^{\circledR}$ eye test. The color of the lower inner eyelid is examined and compared to a color chart. The chart designates color to a number ranging from one to five, five being the highest level of anemia or the most unfavorable condition. The test was named for and developed by Dr. Faffa Malan (FAffa MAlan CHArt; Van Wyk and Gareth, 2002). However, it has been noted that some animals are naturally anemic at some stages of growth. These stages of natural anemia may include at birth and at three months of age (Krull, 1969).

Another method used to determine the level of parasite infestation in sheep is to count the eggs that are expelled in the feces. Knowing how many eggs a female adult nematode produces the level of infestation can be estimated. Estimation of infestation is done on an egg per gram ratio also called an EPG. Eggs per gram from different levels of infection will be different for different species of nematodes. Under optimal conditions $\left(33.3^{\circ} \mathrm{C}\right)$ eggs can develop into infective larvae in 60 to 65 hours (Krull, 1969).

Packed cell volume (PCV) is an indicator of the concentration of red blood cells in an animal's vascular system. A sheep with a high level of infection will be deficient in red blood cells. When the PCV drops below nineteen, the animal is considered anemic (Kaplan, 2004). 
Packed cell volume is determined by centrifuging a small blood sample. A low PCV can be a symptom of $H$. contortus infection.

It is well documented that the primary hosts for $H$. contortus are ruminants. The abomasum is the site of infestation in sheep and goats (Foreyt, 2001). It has been noted that cattle become infected with $H$. contortus only when exposed to sheep and goats. Studies in Australia show that $H$. contortus is the species most likely to infect sheep where another species, known as H. placei, infect cattle (Krull, 1969). It was shown in the Australian research that calves infected with $H$. contortus developed resistance and were then less likely to be infected by H. placei (Krull, 1969).

Other animals have shown the ability to harbor $H$. contortus in their digestive system for a short time. These include mice, chinchillas, jirds, guinea pigs and even humans. In the search for a model to serve as a laboratory host for $H$. contortus it was discovered that the rodent known as the jird was susceptible to $H$. contortus infection (Lee et al., 1990). This laboratory host could be useful in anthelmintic research as it can be raised in a lab environment with ease. $H$. contortus is known to survive in mice for 72 hours (Lee et al., 1990). Guinea pigs were also tested as a possible host but it was determined that the fourth stage larvae did not survive in the internal environment of this animal for more than a week (Lee et al., 1990). Alpacas and lamas are known hosts for $H$. contortus and the FAMACHA score chart has been used to identify an infected animal. It is very rare for a human to be infected by $H$. contortus but this was reported by Arfaa in 1973. 


\section{Extraction from Forage}

The Baermann technique is used for the separation of motile parasites, such as the L3 stage of $H$. contortus, from other materials such as soil, forage, or fecal or material. The mechanism of the technique depends on it being drawn out into the water where inevitably the nematode swims and settles to the bottom of the funnel. After a time a stop cock at the bottom of the funnel can be opened to drain off the bottom portion of the water that contains ideally only the nematodes in the sample. This technique is made up of the following steps (Foreyt, 2001):

1. Place warm water $\left(25^{\circ} \mathrm{C}\right)$ in a glass funnel with a stop cock.

2. Wrap $5 \mathrm{~g}$ of feces in two layers of gauze and place in the water.

3. After 8 hours, withdraw the bottom $10-15 \mathrm{ml}$ of fluid from the funnel into a $15-\mathrm{ml}$ centrifuge tube.

4. Centrifuge the tube for 5 minutes at 1,500 rpm.

5. With a pipette, withdraw the bottom 2-3 drops from the centrifuge tube and transfer to a microscope slide.

6. Add a cover slip and examine under the microscope.

According to Rogers (1940) the rate of nematode collection in a Baermann funnel can be dependent upon the age of the L3 larvae and their fat content. This was determined by assuming that the rate of collection in the Baermann funnel is determined by nematode movement and activity. The infectivity, fat content and activity of $H$. contortus L3 larvae were observed at three different temperatures. A relationship between the three factors of interest and rapidly aged larvae was found. Also, when larvae were slowly aged, at cold temperatures, the level of infection of sheep decreased. The nematodes with the larger fat globules were seen to have more 
movement, about 70 moves per minute where those with the smaller fat globules moved at about 40 moves per minute.

Forage removed from the field can be tested for the presence of $H$. contortus L3 larvae. A small sample can be placed directly into the Baermann funnel and allowed to sit for 24 hours or more to extract the nematodes. This method is limited by the size of the forage sample and the minimum 24 hour period of wait required.

In the washing machine method, the forage sample is washed in a modified heavy duty Whirlpool automatic Speed Queen commercial clothes washing machine (capacity $8 \mathrm{~kg}$ ) at a normal cycle that included two washes (Krecek and Maingi, 2003). The machine filter is removed and a drainage pipe that puts wash water through an $25-\mu \mathrm{m}$ aperture Endicot sieve. The larvae do not pass through this sieve. The particles collected in the sieve are rinsed with tap water. The washings are then rinsed through a sieve with larger holes to remove the big debris. Then the Baermann or a sugar floatation method needs be used to further separate the nematode from fine debris.

Sugar flotation can be used to isolate the nematodes from other materials (Krecek and Maingi, 2003). Sediment containing the nematodes is diluted to 10 to $12 \mathrm{ml}$ with water and is placed in a centrifuge tube and spun down for five minutes at 2,500 rpm. Supernatant liquid is discarded and a solution of $484.5 \mathrm{~g}$ dissolved sugar in $100 \mathrm{ml}$ water is added to the precipitate to give a specific gravity of 1.18 . The liquid is centrifuged at $2,500 \mathrm{rpm}$ for 5 minutes at $15^{\circ} \mathrm{C}$. The supernatant liquid contains the nematodes and is poured over a $25-\mu \mathrm{m}$ sieve. The sieve is washed with water to clean the sugar solution off the nematodes and the deposited nematodes and debris are placed into centrifuge tubes with water. The tube is centrifuged at 2,500 rpm for 5 minutes, the supernatant liquid discarded and clean water added to make the volume $10 \mathrm{ml}$. The 
liquid and the sediment are mixed. Two, 1-ml aliquot counts are taken and examined under a microscope after staining with iodine.

Krecek and Maingi (2003) compared the washing machine method combined with the sugar floatation method described above against a method of hand agitating the forage with water combined with the Baermann funnel technique. They discovered that the washing machine method combined with the sugar floatation method had a recovery rate of nematodes from the field ranged from 18 to $41 \%$ while recovery using hand washing combined with the Baermann method ranged from 0 to $27 \%$.

It has been noted by Veglia (1915) that it takes the L3 over 10 minutes to settle in a test tube and they will attempt to return to the surface of the water if the test tube is placed in direct sunlight. This is an important issue when the volume of a sample containing $H$. contortus L3 needs to be reduced for counting as the upper portion of the sample can be siphoned off.

\section{Use of Chickens}

Among animals known not to be infected with $H$. contortus are the horse, the pig, the donkey, the mule and avian species such as chickens, geese and quail. While chickens are susceptible to some types of internal parasites, $H$. contortus is not one of them. Chickens could be used to remove the infective larval stage from a field if they eat the forage harboring this stage of the pest.

Grasses have been evaluated in the chicken diet. For example, bluegrass clippings are reported to be a better food source than alfalfa meal, a good source of protein (Young et al., 1982). Clover, a legume grown commonly as forage for sheep, can also serve as a source of protein for the chickens when dried (Young et al., 1982). Chickens can feed on low growing 
forage where infective larvae of $H$. contortus are known to be concentrated. Furthermore, chickens can benefit from having access to the insects and seeds in the pasture providing additional nutrients for them (Luttmann and Luttmann, 1976). Mature forage is difficult for chickens to digest and they fare better on young and tender shoots (Luttmann and Luttman, 1976).

Chickens also exhibit a natural scratching behavior. They scratch the ground to stir up soil for dust baths and to obtain grit to aid in the digestion of feed. The act of scratching uproots the forage plants and often creates bare spots on the ground. This behavior could be advantageous in the removal of $H$. contortus from the field before the larvae reach the infective stage. The first and second stage larvae reside in the fecal pellets and must feed on microbes present in the feces. Chickens will scratch apart this pellet and possibly remove the larvae from its food source. Ingestion of these larvae could also occur as the chicken searches for grit. Feces has also been found in the gut of the chickens (Antell and Ciszuk, 2006). The first and second stage larvae are not as resistant to desiccation as the egg and the infective stage. This means that the larvae in the first and second stage have a higher chance of being killed. It was also found that no first or second stage larvae were found if there were no fecal pellets left in the field after being placed there (Levine et al, 1974).

Chickens have been used in other parasite control program. An experiment done by Hassan et al. (1992) in Kenya, tested the chicken's ability to control tick populations in cattle. The exotic chickens used required 8 to 10 weeks to adapt to tick predation. They also found that chickens 1 to 3 weeks of age consumed more ticks in a confined system and chickens 4 to 6 months of age consumed more ticks in an open area. They concluded that chickens could reasonably be used to control ticks. 
Several methods have been used to determine the amount of forage consumed by domestic and wild birds. These methods include but are not limited to comparing forage heights of plots where chickens had been and where chickens were absent, analyzing the gut contents, and the examination of the fecal material (Antell and Ciszuk, 2006). Two experiments were conducted by Antell and Ciszuk (2006) dealing with forage intake of chickens in relation to their crop content. Their first experiment involved 120 hens kept in an old cow pasture with three mobile houses. They were fed whole wheat and oats with grit. These hens were slaughtered and some of their crop's contents were removed, sorted and dried. Forty-two were slaughtered at noon and forty-two were slaughtered at dusk.

In their second experiment 18 hens, that had been free range, were placed in individual cages indoors and offered a weighed amount of forage (consisting mostly of timothy) and supplementary feed, ad libitum. They were kept for a total of five days in this environment before data collection started and on the tenth day they were slaughtered. The fecal material was collected over the last three days and was used for nutritional analysis to calculate the apparent metabolizeable energy. Intake analysis used the crop content to take into account the passage of feed out of the crop. Some forage may remain in the crop for a period greater than one day.

The experimenters determined that hens had fuller crops at dusk than at noon. The crop of the free range chicken contained insects, soil, mammal dung and grit. Variations existed between chickens as each animal has its own preferences for what it will consume. The crops of some chickens only contained leaves from pasture while those of others contained pieces of all varieties of forage they were exposed to.

In Antell and Ciszuk's second experiment all but two crops contained grass blades. They noted that only two of the chickens could be observed consuming all forage species present 
while the others were more selective or had a forage preference. Grass consumption for each chicken ranged from 13 to $130 \mathrm{~g}$ fresh weight per hen over five days. Other sources have identified factors that influence the rate of forage consumption by the chicken. Wood (1961) analyzed temperature data and post mortem crop contents of 600 white leghorn pullets over three years, 1955, 1957, and 1958. A close fit of the data could be seen when the two sets of data were plotted, indicating that chickens will consume more forage when allowed the comfort of shade.

\section{Other Controls}

Other means for controlling $H$. contortus approved for organic production have been tested with positive results. These methods include the use of garlic and sulla (Hedysarum coronarium) extract which is a possible means of reducing $H$. contortus worms in lambs when they graze in pastures containing these plants. In their in vitro experiments, Barrau et al. (2005) showed activity of sainfoin (Onobrychis viciifolia Scop.) extract against H. contortus and confirmed the results of Paolini et al. (2004) who showed that sainfoin extracts would inhibit the development of the L3 stage of $H$. contortus. H. coronarium was shown to reduce the fecal egg count of grazing lambs. These same lambs showed reduced internal parasite infestation including H. contortus compared to control lambs. H. coronarium is a difficult crop to manage and it may only be effective when fed for long periods of time (Rahmann and Seip, 2006).

The use of dietary minerals for controlling $H$. contortus have also found their way into scientific studies. Animals not given extra cobalt had lower levels of the worms in comparison to sheep that were fed cobalt in addition to a basal diet. The lambs fed cobalt had more worms and more of the female $H$. contortus were gravid or carrying eggs. Furthermore, the average worm length in cobalt fed sheep was higher than that of sheep that were on a basal diet (Krull, 
1969). In a separate study, it was discovered that sheep given trace minerals and steamed bone meal were less susceptible to anemia (Krull, 1969).

A biological control with the use of a nematode trapping fungus is a method being studied to control H. contortus. The nematode trapping fungus Duddingtonia flagrans's ability to trap the three animal parasitic nematodes Teladorsagia circumcincta, Trichostrongylus colubriformis and H. contortus in their free living life stages was tested by Paraud et al. (2005). Goats were used as the source of the parasite and the Baermann method was used to recover the nematodes for treatment comparison. The results showed that, out of the three tested, this nematode trapping fungus was most effective in controlling H. contortus at $28^{\circ} \mathrm{C}$.

Administration of chemicals is the normal method for controlling this parasite when preventative measures fail. Frequently, a schedule is used to treat the sheep irrespective of the level of infestation. This routine treatment allows the nematode to become resistant to the drug as only the ones resistant to the drug can live to pass on their genes to their offspring. With each treatment more susceptible nematodes are killed off thus leaving behind those that are not killed by the chemical. Drugs often used include Ivermectin $\mathbb{C}$, chemical name and Panacur $\mathbb{C}$, chemical name Fembandazol. These and others are administered in a liquid form or in the feed of the animals but they are also available in other forms (Krull, 1969). For example, a copper and nicotine sulfate combination can be bought in a capsule. This is an old remedy for the control of $H$. contortus in sheep. Nicotine sulfate administered to a lamb in amounts greater than 207.4 mg may kill the animal.

While chemicals are effectively used in conventional agriculture to control the nematode in the host, chemicals applied to the soil containing the free-living stages of the nematode have yet to show practicality or effectiveness. An example of a chemical control applied to soil is 
fumigation with methyl bromide. This method was found to be too laborious to make treatment over large areas practical. Other controls are also possible but for the most part the infective stage of animal parasitic nematodes are more resistant to chemicals than plant and soil nematodes (Levine, 1969). Thus chemicals used to control animal parasitic nematodes in the soil will affect non target nematodes.

Another form of control is called a self-cure. This is where an animal, once infected by a large number of the nematode expels adult nematodes from the body (Olsen, 1974). Different breeds of sheep have different levels of self-cure ability. It has been documented that the red masai sheep, from South Africa, show more resistance to the worm than sheep that are imported, such as the merino (Elmer et al., 1989). Self-cure comes about when a large quantity of exsheathing fluid from L3 nematodes enters the sheep's body. In this fluid an antigen is found that causes an inflammation reaction in the sheep. This inflammation expelled the nematodes from the body of the would-be-host (Elmer et al., 1989). Also, secondary infection nematodes, nematodes infecting a sheep that has been infected in the past, are more likely to be expelled than the nematodes in the initial infection (Elmer et al., 1989).

\section{Conclusions Based on Research}

Previous research on $\mathrm{H}$. contortus describes the extreme limitations under which this worm can survive in the environment. If the stages prior to the $\mathrm{L} 3$ have favorable environmental conditions then, the L3 can persist longer in the environment and have a better chance in infecting a suitable host (Levine, 1974). Also, without moisture the nematode cannot climb forage and is incapable of infecting sheep (Veglia, 1915). Furthermore, temperatures below freezing are required to incapacitate the L3 and high temperatures aid in drying. There is 
research in nematode trapping fungi but none can be found examining the competition of the $H$. contortus free living stages with other free living nematodes, animal parasitic or otherwise. There is discussion from Rees (1948) on plants that are encouraging climbing by the L3 but not development of species that the L3 might not be able to climb at all, or that hinders the L3's climbing. Also, little research can be found on specifically what happens to the nematode once consumed by a non host, except for research done by Lee et al. (1990).

\section{Materials and Methods}

Research was done in pastures at the WVU organic research farm in May, June, and July of 2008. Three plots, 7 x 14 m, were chosen within the pastures. Pastures were on predominantly Dormont silt loam (fine-loamy, mixed, mesic, Ultic Hapludalfs), in the first and second trials, and Guernsey silt loam (fine, mixed, mesic, Typic Hapludalfs) in the third trial. The main components in the pasture were Dactylis glomerata, Festuca arundinacea and Poa pratensis. There were three treatments (forage removal methods) applied in each of the three trials. At the start of each trial a pasture plot was grazed by twenty-three sheep (two rams, one wether, one lamb and eighteen ewes) at night (7:00 pm to 7:00 am; see Table 1 for dates) and the sheep were then removed. Water was placed at both ends of the pasture to encourage the sheep to spread out. In the third plot, the area sheep grazed was expanded to $30 \times 40 \mathrm{~m}$. Feces were collected from another pasture area (being grazed) diluted in water and stirred to create a homogeneous slurry with an approximate ratio of $65: 35$ feces to water. Fifty $\mathrm{ml}$ of this slurry was poured into a pile every meter in a grid pattern over the area. The trials were called the first, second, and third and the forage removal methods were control, chicken, and mowed. 
Two weeks after the sheep were removed from the pasture, forage removal methods were applied to sub-plots within the plot area. The sub-plots were randomly selected by tossing a child's playground ball over the shoulder and each marked with four corner stakes. The subplots measured $1.0 \times 0.5 \mathrm{~m}$. Four sub-plots served as untreated control plots. Four sub-plots were mowed with hand clippers to a height of 2 to $3 \mathrm{~cm}$ and the forage collected. Four of the sub-plots were grazed with chickens. In the first trial three hens, leghorns, approximately one year old, actively laying eggs, were placed on each sub-plot. They were randomly selected each day from a pool of 14 hens so that no one plot got a chicken that had high or low affinity for grazing pasture. Hens were placed on pasture at 7:00 am and removed at approximately 7:00 pm on three to five successive days until the residual forage was less than $3 \mathrm{~cm}$ height. The same pool of hens was used for each trial. In the second and third trials the number of chickens on each successive day was reduced based on observation of forage quantity, to reduce trampling. Chickens were given water free-choice and provided relief from the sun with a cloth placed over half of the sub-plot. The chickens were enclosed with a chicken wire fence wrapped around the four corner posts that encompassed the entirety of the sub-plot. On the same day that the forage removal methods were applied, four $1.0 \times 0.5 \mathrm{~m}$ areas were clipped at ground level will be referred to as pretreatment low samples. Forage removed from the mowed sub-plots will be referred to as pretreatment high samples.

Two weeks after the hens were removed, the forage in the mowed, chicken, and control sub-plots was clipped to ground level with hand clippers, and collected. The clippers were washed and gloves were changed between sub-plots. The clippers were placed at the soil surface and all forage in the sub-plot was cut and removed. The cut forage was placed in a brown paper bag and labeled for transport to the lab. All clippings were taken between the hours of 7:00 and 
9:00 am. In the first trial only, soil surface scrapings were taken with a knife. Forage from odd numbered sub-plots was analyzed on the same day samples were collected and forage from even numbered sub-plots was refrigerated and analyzed on the next day.

For larger samples a method is needed to concentrate the nematodes into a manageable sample and the washing machine provides such a method. In the lab, all forage from a sub-plot was placed in a mesh bag, with $0.5 \mathrm{~cm}$ holes in it, and the bag was tied. The bag was then placed in the washing machine and it was turned on to delicate cycle with the load size set between small and medium. The machine was put through two wash cycles with no rinse cycle. Washings from the washing machine were passed through a hose into a bath tub that directed the water to a $27 \mu \mathrm{m}$-pore sieve. The water was watched carefully to ensure that the sieve did not overflow. The water that passed through the sieve went directly down a drain.

The mesh bag with the washed forage was then removed from the washing machine, and the forage removed and replaced in the brown paper bag in which it had been collected. The mesh bag was then replaced in the washing machine where it was washed as a mini load and the washings put through the sieve. The material collected in the sieve was then rinsed into a pitcher and poured through a set of sieves that removed the bigger particles. The last sieve was again the $27 \mu \mathrm{m}$-pore sieve. The brown paper bag containing the washed forage was placed in a drying oven and dried at a minimum of $60^{\circ} \mathrm{C}$ for 1 day or $40^{\circ} \mathrm{C}$ for 2 days. Dry weight was recorded and the number of infective larvae per gram of dry forage was determined. Material collected in the $27 \mu \mathrm{m}$-pore sieve was placed on a Kleenex $\subseteq$ tissue on a $1.5 \mathrm{~mm}$ screen in a Baermann funnel filled with tap water. After 24 hours or more the lower 10 to $15 \mathrm{ml}$ was drawn off into a test tube and the nematodes were allowed 15 minutes to settle to the bottom of the tube. The upper $10 \mathrm{ml}$ were vacuumed off discarded and the test tube was capped and shaken briefly 
by hand and then gently stirred mechanically for 5 to 10 minutes to break up any nematode knots that may have formed as a result of nematode swarming behavior. The solution was then poured into a dish $6.35 \mathrm{~cm}$ in diameter and $0.635 \mathrm{~cm}$ deep with 1 to 2 drops of providone iodine and number of infective larva in one-tenth of the area of the dish was counted at 100x magnification.

Table 1: Timetable of actions in each trial.

Action

Dates for each trial

\begin{tabular}{lccc}
\hline & First & Second & Third \\
\hline $\begin{array}{l}\text { Plot grazed with sheep } \\
\begin{array}{l}\text { Hens moved in, sub-plots mowed and } \\
\text { pretreatment (low and high) forage samples } \\
\text { clipped }\end{array}\end{array}$ April 24 - May 11 & May 13 - 15 & June 12 \\
$\begin{array}{l}\text { Chickens removed from sub-plots } \\
\text { Chicken, mowed, and control sub-plots clipped }\end{array}$ & May 12 & May 29 & June 24 \\
\hline
\end{tabular}

Analysis of variance was used in the PROC GLM procedure in SAS( Copyright 19992001 by SAS Institute Inc., Cary, NC, Release 8.2 (TS2M0). The experiment was as a randomized design with four replications, though the trials were restricted. There were four replications per treatment with three periods: first, second and third. The experimental unit was the $1.0 \times 0.5 \mathrm{~m}$ sub-plot. Two analyses were done. One included pretreatment (low and high) and one included only the three treatments. The analysis including the pretreatment samples was done in order to contrast the pretreatment high and low and to contrast the pretreatment low with the three treatments. 


\section{Results and Discussion}

The pretreatment samples were taken when the forage removal methods were applied, two weeks after grazing with sheep. The pretreatment high and low samples did not differ significantly in the number of nematodes per gram forage DM or per sub-plot (Tables 2 and 3). Since both were clipped at the same time the lack of difference in nematode counts implies that no infective larvae were present in the lower 2 to $3 \mathrm{~cm}$ of the herbage.

It was expected that the number of nematodes recovered would have been higher in the forage cut at ground level as Rees (1948) found the majority of $H$. contortus nematodes in the first $\mathrm{cm}$ of grass above the ground, suggesting that the infective larvae were either still developing, from the egg, from L1, or from L2, or the nematodes were not actively climbing the forage. As expected, clipping at soil level (pretreatment low) resulted in more forage mass DM than clipping at 2 to $3 \mathrm{~cm}$ (pretreatment high) (Tables 2 and 3). The method used to extract the L3 nematodes from forage has been found to account only for a proportion of the nematodes (Krecek and Maingi, 2003) and the method may not have been sensitive enough to distinguish the difference.

It should be noted that pretreatment low and control forage samples contained more debris, the washings took longer to pass through the sieve, and nematodes were more difficult to count, than forage from the other sub-plots. There is a possibility that more nematodes could have been lost from these samples during processing than from the cleaner pretreatment high, mowed and chicken sub-plot samples.

Regrowth (after forage removal methods were applied) and forage from control sub-plots did not differ significantly in nematode counts from pretreatment low samples (Tables 2 and 3 ). 
Table 2: Model significance levels of the number of nematodes found per gram of forage dry matter (DM) and per sub-plot, and forage mass DM, pretreatments included.

\begin{tabular}{|c|c|c|c|c|}
\hline Effect & $\mathrm{df}$ & $\begin{array}{l}\text { Nematode } \\
\text { per gram } \\
\text { forage } \\
\mathrm{DM} \dagger\end{array}$ & $\begin{array}{l}\text { Nematode } \\
\text { per sub- } \\
\text { plot }\end{array}$ & $\begin{array}{l}\text { Forage mass } \\
\text { DM }\end{array}$ \\
\hline & \# & & $\mathrm{P}>\mathrm{F}$ & \\
\hline Repetition & 3 & 0.8603 & 0.7065 & 0.7425 \\
\hline Treatment and pretreatment & 4 & 0.0487 & 0.5632 & $<0.001$ \\
\hline $\begin{array}{l}\text { Pretreatment low vs chicken, control, and } \\
\text { mowed }\end{array}$ & 1 & 0.0489 & 0.2186 & $<0.0001$ \\
\hline Chicken vs control & 1 & 0.0428 & 0.6121 & $<0.0001$ \\
\hline $\begin{array}{l}\text { Control vs chicken, mowed, and } \\
\text { pretreatment low }\end{array}$ & 1 & 0.2369 & 0.2932 & 0.0114 \\
\hline Pretreatment low vs Pretreatment high & 1 & 0.2074 & 1.0000 & $<0.0001$ \\
\hline Trial & 2 & 0.1142 & 0.3602 & 0.0771 \\
\hline First vs second and third & 1 & 0.6695 & 0.2753 & 0.1632 \\
\hline Second vs third & 1 & 0.0425 & 0.3561 & 0.1984 \\
\hline Trt $x$ Per & 8 & 0.1150 & 0.4023 & 0.0039 \\
\hline
\end{tabular}

†Nematode per sub-plot divided by total gram forage per sub-plot.

Table 3: Effect of treatment and pretreatment on nematodes and forage DM.

\begin{tabular}{lccc}
\hline $\begin{array}{l}\text { Forage removal } \\
\text { treatment }\end{array}$ & $\begin{array}{l}\text { Nematode per gram } \\
\text { forage DM } \dagger\end{array}$ & $\begin{array}{l}\text { Nematode per } \\
\text { sub-plot }\end{array}$ & Forage mass DM \\
\hline Chicken & $\begin{array}{c}\# \\
\text { Control }\end{array}$ & 21 & gram \\
Mowed & 0.99 & 28 & 21.1 \\
Pretreatment low & 0.28 & 18 & 74.7 \\
Pretreatment high & 0.74 & 8 & 38.8 \\
\hline
\end{tabular}

†Nematode per sub-plot divided by total gram forage per sub-plot.

Microclimate factors alter the ratio of nematodes in the forage compared to those in the soil. Forage was clipped between 7:00 and 9:00 am and some nematodes are expected to be in 
the forage layer at this time. According to Rees (1948) and Krecek (1995) a higher concentration of nematodes may be found in conditions usually present earlier in the day. $H$. contortus L3 climb forage depending on the light intensity, relative humidity, air temperature and soil moisture. Micrometeorlogical data were not taken so the conditions at the soil level under forage cover are unknown. However, the maximum and minimum temperatures and precipitation, for the days on which the forage was collected are listed in Table 4. On days with no precipitation dew was observed on the forage at the time of sampling so that the nematodes did have a medium for climbing forage. The grass blades may not have had a moisture film to allow movement due to a low relative humidity and too much sunlight may have been reaching the crown of the plants. According to Krecek et al. (1995) air temperature has the most significant effect on the nematodes movement in forage and the days on which pretreatment (high and low) samples were taken had lower temperatures when compared to the sampling days of the mowed, chicken, and control plots.

Table 4: Maximum and minimum temperatures and precipitation for the days on which forage was clipped.

\begin{tabular}{|c|c|c|c|c|c|}
\hline & Trial & Plots clipped & Max & Min & Precipitation \\
\hline & & & ${ }^{\circ} \mathrm{C}$ & ${ }^{\circ} \mathrm{C}$ & $\mathrm{mm}$ \\
\hline May 11 & 1 & pretreatment (high and low) & 16.7 & 7.2 & 9.4 \\
\hline May 27 & 2 & pretreatment (high and low) & 23.8 & 12.2 & 6.6 \\
\hline May 30 & 1 & $\begin{array}{l}\text { chicken, mowed, and } \\
\text { control }\end{array}$ & 27.2 & 10 & 0 \\
\hline June 12 & 2 & $\begin{array}{l}\text { chicken, mowed, and } \\
\text { control }\end{array}$ & 32.2 & 15 & 0 \\
\hline June 24 & 3 & pretreatment (high and low) & 25.5 & 11.1 & 0 \\
\hline July 11 & 3 & $\begin{array}{l}\text { chicken, mowed, and } \\
\text { control }\end{array}$ & 28.8 & 13.8 & 0 \\
\hline
\end{tabular}

The null hypothesis that there is no effect of the treatments was accepted (Table 5). There was no significant difference between the three forage removal methods in terms of 
nematodes per gram of forage DM or per sub-plot. There was no significant difference between the forage removal methods in the total number of nematodes per sub-plot (Table 5). Numerically, the control sub-plot had the highest and the mowed plot the lowest counts of nematodes per sub-plot (Table 3). If the chickens removed nematodes from the sub-plot we would have expected the counts to be lower in the subsequent regrowth compared to the control. This was the case. The nematode count in regrowth from chicken sub-plots was seven less than from the control. In a similar way the nematode count in the regrowth from mowed sub-plots was lower than the control. Although the difference between the mowed, chicken and control sub-plots was not significant it may represent a trend showing that chickens decreased the number of nematodes by consuming herbage. It was expected that the control sub-plot would have the highest count of nematodes because no forage was removed and the forage creates a favorable environment for the nematodes with protection from sunlight and the potential for a high relative humidity (Shorb 1942). Disturbing the forage canopy layer would expose nematodes to unfavorable conditions. The chicken sub-plot had the highest number of nematodes per gram of forage dry matter (Table 3). The chicken sub-plot also had the least amount of regrowth (Table 3). While the chickens were grazing, observations were made showing that they first removed the forage in the center of the sub-plot. The chickens had a high preference for earthworms and they scratched at the forage. In their hunt for earthworms they started in the center of the plot and a bare spot developed. This bare spot enlarged each day, taking up $50 \%$ of the plot on the third or fourth day. If the forage was not eaten but instead died due to desiccation from the scratching chickens, the nematodes would have had a chance to swim to the remaining forage, especially since the forage was removed slowly and the chickens were 
removed at night. Regrowth in the plots was not uniform being much higher around the edges of the plot than in the center.

Table 5: Model significance levels of the number of nematodes found per gram of forage dry matter (DM) and per sub-plot, and forage mass DM, treatments only.

\begin{tabular}{lcccc}
\hline Effect & df & $\begin{array}{l}\text { Nematode } \\
\text { per gram } \\
\text { forage } \\
\text { DM } \dagger\end{array}$ & $\begin{array}{l}\text { Nematode } \\
\text { per sub- } \\
\text { plot }\end{array}$ & $\begin{array}{l}\text { Forage mass } \\
\text { DM }\end{array}$ \\
\cline { 5 - 5 } & $\#$ & & P>F & \\
Repetition & 3 & 0.8391 & 0.5491 & 0.6968 \\
Treatment & 2 & 0.2048 & 0.8212 & $<0.0001$ \\
$\quad$ Chicken vs control & 1 & 0.0818 & 0.6538 & $<0.0001$ \\
$\quad$ Control vs mowed & 1 & 0.2532 & 0.5506 & 0.0018 \\
$\quad$ Control vs chicken and mowed & 1 & 0.0975 & 0.5465 & $<0.0001$ \\
Trial & 2 & 0.1029 & 0.2746 & 0.0771 \\
$\quad$ First vs second and third & 1 & 0.6480 & 0.2746 & 0.0250 \\
$\quad$ Second vs third & 1 & 0.0385 & 0.3561 & 0.9711 \\
Trt x Per & 4 & 0.1850 & 0.4435 & 0.0033 \\
\hline
\end{tabular}

†Nematode per sub-plot divided by total gram forage per sub-plot.

Table 6: Effect of trial on nematodes and forage DM.

\begin{tabular}{llll}
\hline Effect & $\begin{array}{l}\text { Nematode per gram forage } \\
\text { DM }\end{array}$ & Nematode per sub-plot & Forage mass DM \\
\hline \multirow{2}{*}{ First } & $\#$ & $\#$ & gram \\
Second & 0.60 & 28.88 & 63.89 \\
Third & 0.80 & 20.63 & 58.03 \\
& 0.18 & 8.75 & 44.78 \\
\hline
\end{tabular}

The second trial was significantly higher than the third trial in terms of nematodes per gram of forage DM (Table 5 and 6). This difference is heavily influenced by forage mass. A decrease in forage mass over time would be expected as higher temperatures decrease regrowth. We would expect the number of nematodes in the trials to be influences by the egg production of 
the gravid females inside the animal. There is a natural rise in the number of eggs produced in the spring (Agyei et al. 1991) and it is logical to conclude that the number of eggs produced may have decreased in June. Also, higher temperatures (Table 7) makes the nematode more prone to drying and desiccation. Furthermore, regrowth in earlier trials may be from reproductive buds, the growth rate of which is higher than the vegetative buds which predominated in the third trials. There were differences in forage mass dry matter between the three forage removal methods (Table 5). There was also an interaction between trial and forage removal method for forage mass dry matter and Figure 1 shows this interaction. High forage mass DM in the early control was probably due to reproductive growth. Growth rate of cool season grasses is expected to decrease in midsummer due to higher temperatures (Table 7) and the pressure from the chickens and the mowing may have caused additional stress reducing rate of recovery. The chicken's scratching and grazing behavior reduced the forage regrowth compared to the other methods of forage removal. The activity of the chickens caused plant upheaval and apical meristem death. The control sub-plots were allowed to grow with no interference and therefore had the highest regrowth. The control out produced the mowed plot because the plants had a longer growth period.

In spite of the fact that chickens were exposed to pasture conditions two weeks before the field experiment commenced, two weeks may not have been enough time to allow them to adjust to the outdoor conditions, to be in close proximity to each other and to learn how to forage. Before the experiment began chickens were put on a $3 \times 5 \mathrm{~m}$ plot and rotated randomly into a 1.0 x $0.5 \mathrm{~m}$ plot three at a time, for ten days. Prior to the experiment, the chickens were confined indoors in individual cages and were never allowed outdoors. Hassan et al. (1992) reported that 
it took 8 to 10 weeks for chickens to adapt to predate on ticks, so it can be expected that they would need more than two weeks to adapt to grazing.

Figure 1: Effect of forage removal method and trial on forage mass DM.

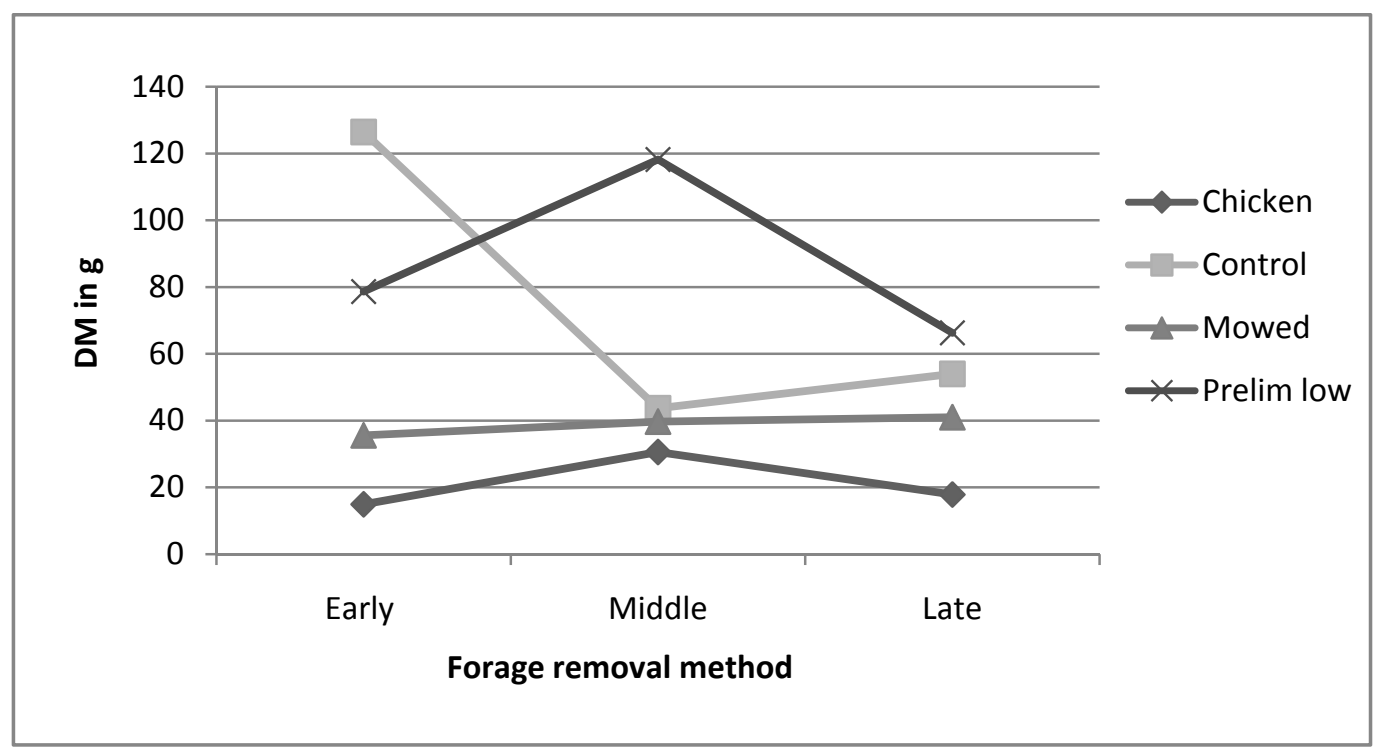

Table 7: Average monthly temperature for the months of the experiment, deviation from the thirty year average and monthly precipitation (Morgantown airport $1 \mathrm{~km}$ from experiment site).

\begin{tabular}{lllll}
\hline Month & Average & Normal averaget & Precipitation & $\begin{array}{l}\text { Average } \\
\text { precipitationt }\end{array}$ \\
\hline & ${ }^{\circ} \mathrm{C}$ & ${ }^{\circ} \mathrm{C}$ & $\mathrm{mm}$ & Mm \\
April & 13.2 & 11.2 & 85 & 89 \\
May & 14.4 & 16.4 & 152 & 92 \\
June & 21.5 & 20.8 & 169 & 104 \\
July & 22.5 & 22.7 & 199 & 105 \\
\hline
\end{tabular}

†From the thirty year average of 1946 to 1978.

\section{SUGGESTIONS FOR FURTHER RESEARCH}

Under the conditions of the experiment the use of these chickens failed to significantly reduce the number of $H$. contortus infective larvae on pasture. The following changes are 
suggested to better determine if, in fact, chickens can contribute to the control of $H$. contortus in sheep.

Variations of the hypothesis could be tested with the following suggested changes in procedure:

1. Use a bigger area for chickens (Hassan et al. 1992).

2. Use a breed of chicken more adapted to grazing.

3. Put the chickens on only from 4 to 8 am and 7 to $10 \mathrm{pm}$ so they graze only at the times when nematodes are on forage (Rees, 1948).

4. Take representative soil samples from each sub-plot and put the soil directly in Baermann funnel.

5. Place the recovered nematodes in a solution of 1 to $3 \%$ hydrochloric acid solution. The animal parasitic nematodes such as $H$. contortus can survive under these conditions where the soil and plant nematodes all die (Shorb, 1937).

6. Allow a greater adjustment time for chickens not used to grazing. Eight to ten weeks should be sufficient as suggested by Hassan et al. (1992).

7. Use younger chickens. Hassan et al. found that chickens 1 to 3 weeks of age were the most efficient tick predators. 


\section{SOURCES}

Agyei, A. D., D. Sapong, and A. J. Probert. 1991. Periparturient rise in faecal nematode egg counts in west African dwarf sheep in southern Ghana in the absence of arrested strongyle larvae. Vet. Parasitol. 39:79-88.

Antell, S., and P. Ciszuk. 2006. Forage consumption of laying hens - the crop content as an indicator of feed intake and AME content of ingested forage. Arch. Geflügelk. 70:154160.

Arfaa, E. G. 1973. First report of human infection with Haemonchus contortus, Ostertagia ostertagi, and Marshallagia marshalli (Family Trichostrongylidae) in Iran. J. Parasitol. 76:68-170.

Ayalew, L., and B. E. P. Murphy. 1986. In vitro demonstration of in utero larval development in an oviparous parasitic nematode: Haemonchus contortus. Parasitol. 93:371-381.

Barrau, E., N. Fabre, I. Fouraste, and H. Hoste. 2005. Effect of bioactive compounds from sainfoin (Onobrychis viciifolia Scop.) on the in vitro larval migration of Haemonchus contortus: Role of tannins and flavonolglycosides. Parasitol. 131:531-538.

Beckage, N. E. (ed.) 1997. Parasites and pathogens: Effects on host hormones and behavior. Chapman and Hall, New York, NY.

Coyne, M. J., G. Smith, and C. Johnstone. 1991. A study of the mortality and fecundity of Haemonchus contortus in sheep following experimental infections. Australian Soc. Parisitol. 21: 847-853. 
Dinaburg, A. G. 1944. Development and survival under outdoor conditions of eggs and larvae of the common ruminant stomach worm, Haemonchus contortus. J. Ag. Res. 69:11.

Doney, J. C., Jr. 1990. Quantitative assay of nematode biocontrol agent activity and its use in clandosan amended soil. M.S. Thesis. West Virginia University, Morgantown, WV.

Elmer, N. R., G. A. Noble, G. A. Schad, and A. J. Macinnes. 1989. Parasitology: The biology of animal parasites. Lea and Febiger, Philadelphia, PA.

Foreyt, W. J. 2001. Veterinary parasitology reference manual. $5^{\text {th }}$ ed. Iowa State Univ. Press, Ames, IA.

Gamble, H. R., J. R. Lichtenfels, and J. P. Purcell. 1989. Light and scanning electron microscopy of the ecdysis of Haemonchus contortus infective larvae. J. Parasitol. 75:303-307.

Hassan, S. M, O. O. Dipeolu, and D. M. Munyinyi. 1992. Influence of exposure period and management methods on the effectiveness of chickens as predators of ticks infesting cattle. Vet. Parasitol. 43: 301-309.

Hertzberg, H., U. Huwyler, L. Kohler, S. Rehbein, and M. Wanner. 2002. Kinetics of exsheathment of infective ovine and bovine strongylid larvae in vivo and in vitro. Parasitol. 125:65-70.

Khalil, M. 1922. Thermotropism in Ankylostome larvae. Proc. Roy. Soc. Med. 15:16-18.

Kaplan, R. M., J. M. Burke, T. H. Terrill, J. E. Miller, W. R. Getz, S. Mobini, E. Valencia, M. J. Williams, L. H. Williamson, M. Larsen, and A. F. Vatta. 2004. Validation of the FAMACHA $^{\circledR}$ eye color chart for detecting clinical anemia in sheep and goats on farms in the southern United States. Vet. Parisitol. 123:105-120. 
Krecek, R. C., R. Hartman, H. T. Groenveld, and A. Thorne. 1995. Microclimatic effect on vertical migration of Haemonchus contortus and Haemonchus placei third-stage larvae on irrigated Kikuyu pasture. Onderstepoort J. Vet. Res. 62:117-122.

Krecek, R. C., and N. Maingi. 2003. Comparison of two techniques used for the recovery of third-stage strongylid nematode larvae from herbage. Vet. Parisitol. 122:233-243.

Krull, W. 1969. Notes in veterinary parasitology. University Press, Lawrence, KS.

Lee, T. B., G. A. Conder, L. W. Jen, K. S. Marbury, S. S. Johnson, P. M. Guimond, E. M. 1990. A novel anthelmintic model utilizing jirds, Meriones unguiculatus, infected with Haemonchus contortus. J. Parasitol. 46:168-170.

Le Jambre, L. F. 1994. Relationship of blood loss to worm numbers, biomass, and egg production in Haemonchus infected sheep. Intern. J. Parasitol. 25: 269-273.

Levine, N. D. 1969. Chemical control of soil stages of animal-parasitic nematodes. Transactions of the American Microscopical Soc. 88:135-141.

Levine, N. D., M. E. Mansfield, and K. S. Todd, Jr. 1977. The effects of photoperiod during development and of storage on maturation of Haemonchus contortus larvae. J. Parasitol. 63:954-956.

Levine, N. D., K. S. Todd, and P. A. Boatman. 1974. Development and survival of Haemonchus contortus on pasture. American J. Vet. Res. 35:1413-1422.

Luttmann, G., and R. Luttmann. 1976. Chickens in your backyard. Rodale Press. Emmaus, PA. Mönnig, H. O. 1930. Studies on the bionomics of the free-living stages of Trichostrongylus spp. and other parasitic nematodes. Rep. Vet. Res. S. Afr. 16:175. 
Murphy C. R. and R. I. Sommerville. 1983. Reversal of order of ecdysis in Haemonchus contortus (Nematoda). J. Parasitol. 69:368-371.

Noble, E. R., G. A. Noble, G. A. Schad, and A. J. MacInnes. 1989. Parasitology: The biology of animal parasites. $6^{\text {th }}$ ed. Lea and Febiger, Philadelphia, PA.

Olsen, W. O. 1974. Animal parasites: Their life cycles and ecology. $3^{\text {rd }}$ ed. University Park Press, Baltimore, MD.

Paolini, V., I. Fouraste, and H. Hoste. 2004. In vitro effects of three woody plant and sainfoin extracts on 3rd-stage larvae and adult worms of three gastrointestinal nematodes. Parasitol. 129:69-77.

Paraud C ., I. Pors, C. Chicard, and C. Chartier. 2005. Comparative efficacy of the nematodetrapping fungus Duddingtonia flagrans against Haemonchus contortus, Teladorsagia circumcincta and Trichostrongylus colubriformis in goat faeces: influence of the duration and of the temperature of coproculture. Parasitol. Res. 98:207-213.

Rahmann, G., and H. Seip. 2006. Alternative strategies to prevent and control endoparasite diseases in sheep and goat farming systems [Online]. http://orgprints.org/10030/01/08_Rahmann_Endoparasiten_fertig.pdf (verified on 9/02/07).

RVC/FAO. 2008. Guide to veterinary diagnostic parasitology [Online]. http://www.rvc.ac.uk/review/Parasitology/RuminantL3/Introduction.htm (verified 9 Sept. 2008).

Rees, G. D. 1948. Observations on the vertical migration of the third-stage larva of Haemonchus contortus (RUD.) on experimental plots of Lolium perenne S24, micrometeorological factors. M.S. Thesis. University College of Wales, Aberystwyth, UK. 
Rogers, W. P. 1940. The physiological ageing of the infective larvae of Haemonchus contortus. J. Helminthol. 18:183-92.

Sendow, J. 2003. Haemonchus contortus. Animal Diversity Web [Online]. Available at http://animaldiversity.ummz.umich.edu/site/accounts/information/Haemonchus_contortus .html (verified 9 Sept. 2008).

Shorb, D. A. 1937. A method of separating infective larvae of Haemonchus contortus (Trichostrongylidae) from free-living nematodes. Proc. Helminthol. Soc. Wash. 10:1-3.

Shorb, D. A. 1942. Survival on grass plots of eggs and preinfective larvae of the common sheep stomach worm, Haemonchus contortus. J. Parasitol. 29:284-289.

Smith, L. 1942. Parasites of sheep, cattle, swine, and horses in West Virginia. M.S. Thesis. West Virginia University, Morgantown, WV.

Smith, M., V. Burnett, and Rutherglen. 2006. Organic farming: Internal parasites of sheep [Online]. Available at http://www.dpi.vic.gov.au/DPI/nreninf.nsf/childdocs/49A21C225110DAB74A2568B30004DB83-87033AD2C9D2F3F4CA256BC7008360449B49B51BA195265B4A256DEA0027DACB-443A0F7D4AF27778CA25729E0013CF75?open (verified on Sept. 09, 2007).

Tetley, J. H. 1941. Haemonchus contortus eggs: Comparison of those in utero with those recovered from feces, and a statistical method for identifying $H$. contortus eggs in mixed infections. J. Parasitol. 27:453-463.

Vagenas, D. 2007. Estimation of heritabilities and correlations between repeated faecal egg count measurements in lambs facing natural nematode parasite challenge, using a random regression model. J. Ag. Sci. 145:501. 
Van Wyk, J. A., and B. F. Gareth. 2002. The FAMACHA system for managing haemonchosis in sheep and goats by clinically identifying individual animals for treatment. Vet. Res. 33:509-529.

Veglia, F. 1915. The anatomy and life-history of the Haemonchus contortus (Rud.). Dep. Agr. Union S. Africa, Rep. Dir. Vet. Res. 3,4:347-500.

Wood, G. M. 1961. Relation of temperature to quantity of forage consumed by chickens on range. Poultry Sci. 40:1134.

Young, R. J., S. L. Milton, and M. C. Nesheim. 1982. Nutrition of the chicken. Humphrey Press, Ithica, NY. 


\section{APPENDIX}

Table 1: Number of chickens in each sub-plot each day of chicken grazing.

\begin{tabular}{lccc}
\hline & Trial 1 & Trial 2 & Trial 3 \\
\hline & & \# of Chickens & \\
\cline { 2 - 3 } Day 1 & 3 & 3 & 3 \\
Day 2 & 3 & 2 & 2 \\
Day 3 & - & 2 & 2 \\
Day 4 & - & - & 2 \\
\hline
\end{tabular}




\section{VITA}

\section{Jessica Harley Nicole Eddy}

Address:

\section{Education:}

Professional

Experience:

Work Experience:

Honors and Activities: $5106^{\text {th }}$ street

Email: Jessica.jharley.eddy@gmail.com

(304) $363-8006$

Cell: (304) 276-1732

WEST VIRGINIA UNIVERSITY, Morgantown, WV 26506.

Bachelor of Science in Agriculture with a major in Agricultural and Extension

Education. Graduated in May, 2007. GPA= 3.95/4.0 scale.

Intern, Evans’ Knob Organic Farm, Bruceton, WV 26525.

Responsibilities included: harvesting, packaging, data keeping, miscellaneous work, and research during the summer of 2006.

Professional Support Assistant, Natural Resource Analysis Center, Morgantown, WV 26506.

Responsibilities included: file maintenance, database upkeep, software installation and organization during the fall semester of 2006.

Student Teacher, Liberty High School, Clarksburg WV 26301.

Responsibilities included: Coursework planning, SAE visits, The teaching of an adult education class, middle school teaching experience, FFA activities and others in 2007.

Insider, Papa John's Pizza, Fairmont, WV 26554.

Responsibilities include: new employee training, order taking, dough slapping, food preparation, and sanitation. 2001-2007.

West Virginia University, Morgantown, WV 26506.

Awards Received:

- Presidential Award for Excellence in Scholarship. Spring/Fall 2004, Spring/Fall 2005, and Spring 2006.

- 2004 Baughman Scholarship

- 2006 Outstanding Scholarship recognition from Mountaineer Collegiate FFA and Alpha Tau Alpha

\section{Organizations:}

- National Society for Collegiate Scholars

- Alpha Tau Alpha

- Gamma Sigma Delta

- Phi Kappa Phi

- Marion County FFA Alumni

- USA National Karate Federation

Personal Information: D.O.B. 5/30/85; Health: Excellent. Attributes: Motivated, Honest, Trustworthy, and Dedicated. Hobbies: martial arts, reading, writing, and photography. 